\title{
Lapurdum
}

Euskal ikerketen aldizkaria | Revue d'études basques |

Revista de estudios vascos | Basque studies review

$8 \mid 2003$

Numéro VIII

\section{Historia y memoria de un éxodo. La memoria colectiva de los niños vascos refugiados en Francia y en Bélgica, 1936-1940}

Jesus Javier Alonso Carvallés

\section{(2) OpenEdition}

\section{Journals}

\section{Edición electrónica}

URL: http://journals.openedition.org/lapurdum/914

DOI: 10.4000/lapurdum.914

ISSN: 1965-0655

\section{Editor}

IKER

\section{Edición impresa}

Fecha de publicación: 1 noviembre 2003

Paginación: 19-23

ISBN: 9782867813436

ISSN: 1273-3830

\section{Referencia electrónica}

Jesus Javier Alonso Carvallés, « Historia y memoria de un éxodo. La memoria colectiva de los niños vascos refugiados en Francia y en Bélgica, 1936-1940», Lapurdum [En línea], 8 | 2003, Publicado el 01 junio 2009, consultado el 20 abril 2019. URL : http://journals.openedition.org/lapurdum/914 ; DOI : 10.4000/lapurdum.914 


\section{Jesus Javier Alonso Carvallés}

\section{Historia y memoria de un éxodo. La memoria colectiva de los niños vascos refugiados en Francia y en Bélgica, 1936-1940 i.}

Historia y memoria de un éxodo es una investigación que cuenta entre. sus objetivos superar la división entre lo que podemos denominar una historia tradicional, cimentada sobre el documento escrito de carácter oficial y una. nueva historia, abierta a otras formas de acceso a la explicación de los acontecimientos pasados; entre una historia estanca y una historia transdisciplinar que tienda puentes hacia otras disciplinas sociales. Se trata, en definitiva, de una tesis que aborda la historia de la evacuación a Francia y Bélgica de más de 26.000 niños vascos como consecuencia de la Guerra Civil española, y que se ocupa también de la memoria de los protagonistas supervivientes de esa. experiencia infantil.

En el plano de los acontecimientos hemos querido restaurar la multiplicidad, la diversidad de un fenómeno histórico tan singular como fue el éxodo infantil vasco, cuya complejidad histórica apenas aparecía esbozada en la bibliografía anterior. En el ámbito de la memoria, nunca estudiado historiográficamente, nuestro interés se ha portado sobre la articulación y configuración de la misma y, fundamentalmente, sobre el proceso de su construcción colectiva.

Con este doble objetivo de partida, la tesis se ha estructurado en dos partes diferenciadas pero íntimamente ligadas entre sî. Una primera, centrada en la historia del éxodo desde las primeras huidas de 1936 y la evacuación por mar en 1937 hasta el retorno masivo en 1939, y una segunda dedicada a la historia de la construcción y de la formulación actual del recuerdo de esos acontecimientos. Este planteamiento nos ha permitido describir los principales características históricas de los niños vascos refugiados en ambos países

\footnotetext{
I Tesis leída en la Facultad de Geografía e Historia de la Universidad de Salamanca el 3 de abril de 1998. Directora: Pr. Josefina Cuesta Bustillo.
} 
y, paralelamente, plantear un análisis teốrico y metodológico sobre la memoria de las vivencias infantiles de los protagonistas. Para realizar este trabajo hemos trabajado, fundamentalmente, con dos tipos de fuentes: las fuentes documentales y las fuentes orales.

En relación a las primeras ha sido necesario investigar en centros documentales de España, Francia y Bélgica. En primer lugar, destaca la documentación consultada en el Archivo Histórico del Nacionalismo Vasco, de la Fundación Sabino Arana, situado en la localidad vizcaína de Artea, y en el Archivo Histórico Nacional, Sección Guerra Civil de Salamanca, en el Archivo del Ministerio de Asuntos Exteriores y en el Archivo General de la Administración de Alcalá. En Francia hemos centrado nuestra investigación en los Archives du Ministère des Affaires Etrangères, y en la documentación conservada en una quincena de archivos departamentales, poco explotada anteriormente y que se reveló de una gran riqueza, especialmente en los casos de los archivos de los Pyrénées-Atlantiques, Landes, Gironde, CharenteMaritime, Loire-Atlantique, Gard, Vaucluse, Hérault y Tarn. En Bélgica, investigamos en numerosos centros documentales como el Institut Emile Vandervelde, de Bruselas, el Archief en Museum van de Socialistische Arbeidersbeweging (AMSAB) de Gante, el Centre de Recherches et d'Etudes Historiques de la Seconde Guerre Mondiale de la capital belga, y el Archivo del Arzobispado de Malinas, entre otros.

En la primera parte de la tesis, la consulta de una ingente documentación en los citados centros nos ha permitido realizar una serie de novedosas aportaciones historiográficas. Además de poner de manifiesto las causas y las condiciones en las que se iniciaron las masivas evacuaciones infantiles desde los puertos vascos, fundamentalmente tras el bombardeo de Gernika el 26 de abril de 1937, estudiamos el papel preponderante del Gobierno de Euzkadi en su organización, las negociaciones con las autoridades francesas e inglesas y las numerosas expediciones llevadas a cabo, los barcos empleados, sus contingentes... Las fuertes reacciones franquistas en contra de este éxodo humanitario en el cual se vieron implicados, en total, más de 32.000 menores vascos, son también analizadas en esta primera parte y nos permiten comprender mejor el esfuerzo desplegado por las autoridades rebeldes para lograr su repatriación y evitar así la mala imagen causada por esta masiva huida.

La llegada de los niños a las costas francesas, el reparto inicial y su distribución territorial final en Francia y en Bélgica han sido estudiados a fondo. En la tesis se incluyen dieciséis mapas que reflejan de forma detallada las trayectorias y la distribución departamental de los pequeños refugiados en 
ambos países y muestran la enorme dispersión geográfica de este éxodo infantil -hubo refugiados vascos en todos los departamentos franceses, salvo los fronterizos con la Alemania de Hitler, y en todas las provincias belgas- lo que nos permite terminar con la extendida visión reduccionista del fenómeno según la cual los pequeños fueron concentrados casi de forma exclusiva en el departamento de los Bajos Pirineos. Otra de las aportaciones de la tesis es la recuperàción histórica de la figura de Juan Gracia, Consejero socialista de Asistencia Social del Gobierno Vasco, como figura transcendental y principal organizador de las evacuaciones infantiles.

En lo que concierne la acogida de los niños refugiados en ambos países, hemos tratado de demostrar la existencia de una realidad más global y amplia, ya que junto al enorme esfuerzo desplegado por el Gobierno Vasco hemos analizado la labor desarrollada por el Gobierno francés y el establecimiento de colonias y refugios por toda una serie de partidos, sindicatos y agrupaciones de Francia, de Bélgica y de otros países, que pone de relieve la solidaridad despertada por los menores vascos en organizaciones impulsadas desde ámbitos sociales e ideológicos muy diversos. En este sentido, hemos puesto de manifiesto cómo la mayor parte de los niños -más de 7.000 en Francia y por encima de 3.000 en Bélgica-, fueron "apadrinados", es decir acogidos temporalmente en el seno de familias adoptivas implicadas en la lucha antifascista y solidarias con la República española o preocupadas por la suerte de miles de niños, muchos de ellos católicos. Esta realidad dio lugar a una experiencia del exilio completamente diferente de los niños que fueron acogidos en Gran Bretaña o la URSS instalados mayoritariamente en colonias y refugios infantiles.

Otros fenómenos apenas estudiados previamente como la lucha interna entre las propias autoridades republicanas y con el Gobierno Vasco por la tutela jurídica de la infancia evacuada, o la rivalidad en torno a la acogida de los niños vascos en Bélgica entre socialistas y católicos son también abordados en este trabajo. En la parte final, hemos investigado en profundidad los esfuerzos desplegados por las autoridades franquistas para la repatriación de los pequeños, labor en la que contaron con la colaboración de altas instancias militares y eclesiásticas, incluido el delegado apostólico del Vaticano en España Monseñor Antoniutti. No obstante, como demostramos en el trabajo, pese a la enorme campaña propagandística realizada y a las presiones sobre los padres de los pequeños, fueron el final de la Guerra Civil y, sobre todo, el estallido de la guerra europea los dos acontecimientos decisivos que determinaron el retorno a casa de la mayoría de los niños vascos. 
Paralelamente al trabajo sobre fuentes documentales, nuestro trabajo de investigación se extendió a las fuentes orales como la mejor vía para acceder al conocimiento de la memoria colectiva de los protagonistas. Para ello empleamos dos métodos complementarios: el cuestionario escrito y la entrevista. El cuestionario escrito nos aportó toda una serie de datos de carácter histórico y sociológico que fueron muy útiles a la hora de determinar la muestra de población a entrevistar. Posteriormente realizamos un total de 72 entrevistas en profundidad semiestructuradas de carácter abierto y enfocadas hacia la experiencia del exilio. Con esta elección pretendíamos la presencia de cuestiones comunes en todas las entrevistas y, al mismo tiempo, la evocación libre de los informantes ya que lo que más nos interesaba era la percepción subjetiva de sus vivencias, la reconstrucción histórica basada en el recuerdo individualizado de cada protagonista. Además incorporamos a nuestro trabajo una veintena de entrevistas más realizadas previamente por la historiadora María Carmen Uberuaga. En total, hemos trabajado para la tesis sobre un corpus de fuentes orales que superaba las setenta horas de grabación que una vez transcritas superaban las mil páginas.

El análisis de estos relatos nos ha permitido conocer la articulación de la memoria colectiva en tres tiempos bien diferenciados aunque muy relacionados entre sí: el tiempo de guerra, el tiempo de éxodo y el tiempo de posguerra. Para los protagonistas entrevistados la guerra aparece en el recuerdo caracterizada por la pérdida de la infancia, la omnipresencia de los bombardeos, la ausencia de escuela y la vida cotidiana en las calles y en los refugios. Una situación límite en la que la huida al extranjero es considerada como algo inevitable. Por el contrario, el exilio aparece en la memoria colectiva como un período de estabilidad y de paz, lejos de las miserias y de los peligros de la guerra. Unos meses o unos años caracterizados por la recuperación de la infancia perdida durante la guerra, con el retorno a la vida en familia, la vuelta a la escuela, a los juegos, las risas y el compañerismo de las colonias. Un tiempo un tanto mitificado, hasta el punto de que muchos no dudan en referirse a él como los mejores años de su vida. Por último, el retorno a casa y la posguerra son rememorados como las vivencias más negativas. El hambre y la miseria generalizadas, los familiares muertos y represaliados, provocaron un salto prematuro a la madurez que condicionó de forma dramática la vida posterior de muchas personas. Para aquellos que no regresaron, la permanencia significó la trágica experiencia del adiós a los padres y al país que les habían visto nacer. Una ruptura que pesaría como una losa durante largos años. Para unos y para otros alegría y tragedia, experiencias inolvidables y experiencias insufribles son dos caras de una misma historia que no ha deja- 
do indiferente a ninguno de aquellos menores que un día tuvieron que abandonar Euskadi.

En este mismo ámbito del recuerdo, debemos señalar la originalidad del estudio de la construcción de la memoria colectiva de un grupo histórico particular, un campo en el que la historiografía española comienza a dar sus primeros pasos. En nuestro análisis hemos podido discernir, en grandes líneas, la existencia de dos grandes períodos. El primero se extiende entre 1939 y 1967, y puede ser caracterizado como el período del largo silencio ya que en estos años la experiencia de la guerra y el exilio fueron una vivencia personal, interior y raramente compartida. El segundo período discurre entre 1967 y 1997 y se caracteriza por el triunfo de la memoria colectiva o la visión del exilio como una experiencia común, sobre todo a partir de 1987. En nuestra tesis apuntamos al menos cuatro causas fundamentales de esa evolución transcendental ocurrida en los últimos treinta años: la publicación del libro El otro árbol de Guernica de Luis de Castresana en 1967, la consecución de la democracia en España a partir de 1978 y el auge de las reivindicaciones en los años ochenta de los vencidos de la Guerra Civil, la creación en Euskadi de la "Asociación de Niños Evacuados el 37" en 1986 y, por último, la guerra en la antigua Yugoslavia desde 1993. Todos estos acontecimientos tuvieron su importancia en el proceso de construcción colectivo de la memoria aunque, sin duda, el fundamental fue la creación a mediados de los años ochenta de lo que Gérard Namer ha denominado organizaciones de "mémoire-message". Su nacimiento y el impulso por parte de las mismas de diferentes prácticas sociales de conmemoración (reuniones, encuentros, viajes, publicaciones...) ha permitido la eclosión de una memoria colectiva que hasta entonces se encontraba latente entre sus protagonistas y ha producido una profunda transformación en la consideración que los propios protagonistas tenían de su experiencia personal.

Desde hace pocos años estos supervivientes miran atrás de forma colectiva, convencidos de la trascendencia social de su experiencia y de la necesidad de trasmitir a los demás las impresiones de una niñez singular vivida a saltos. 